\title{
Bilateral spontaneous pneumothorax in a term newborn
}

\author{
Vinson James' ${ }^{1}$, Jincy Rajan ${ }^{2}$ \\ From ${ }^{1}$ Consultant, Department of Pediatrics, ${ }^{2}$ Consultant, Department of Obstetrics and Gynecology, Assumption Hospital, Kerala, Wayanad, India.
}

\begin{abstract}
Spontaneous pneumothorax in a full-term, apparently healthy infant is rarely seen, although it is a well-known complication of the respiratory distress syndrome. The management is mostly associated with assisted ventilation, birth trauma, meconium aspiration, or prematurity. We report the case of the occurrence of spontaneous bilateral pneumothorax in a healthy neonate, born by spontaneous vaginal delivery at term in the absence of any known predisposing factors. The baby recovered completely with conservative management with an oxygen-enriched atmosphere and needle thoracentesis. Symptomatic spontaneous pneumothorax is a rare occurrence in term newborns. Bilateral spontaneous pneumothorax has only been described only in a handful of case reports until now. Early recognition of progressive respiratory distress and its immediate management is lifesaving and reduces undue interventions, referrals, escalation of treatment costs, and the hospital stay.
\end{abstract}

Key words: Bilateral pneumothorax, Term neonate, Thoracentesis

$\mathrm{S}$ pontaneous pneumothorax is present shortly after birth in $1-2 \%$ of all infants and may be symptomatic in approximately half of these [1,2]. The incidence of spontaneous neonatal pneumothorax is twice as high in males as compared to female infants [3]. Affected infants usually have a history of fetal distress requiring resuscitation or a difficult delivery with evidence of aspiration of meconium, blood, or mucus. A higher incidence of pneumothorax was noted in neonatal respiratory distress syndrome [4]. Excessive birth weight is also found as a risk factor for the occurrence of spontaneous pneumothorax [3]. The early diagnosis and treatment of neonatal pneumothorax is critical, as it may help to avoid complications and reduce mortality rates. Here, we report a case of spontaneous bilateral pneumothorax in a term neonate who was admitted to our neonatal intensive care unit.

\section{CASE REPORT}

A 26-year-old primipara at term gestation delivered a female baby by lower segment cesarean section in view of breech presentation in our center. The baby cried immediately at birth and did not require resuscitation. Apgar scores were $8 / 10$ and $9 / 10$ at 1 and $5 \mathrm{~min}$, respectively. The antenatal and prenatal course was unremarkable with no evidence of chorioamnionitis, oligohydramnios, or any systemic infection. The mother had regular antenatal check-ups and adequate weight gain during the course of pregnancy. Within

\section{Access this article online}

Received - 29 August 2020

Initial Review - 14 September 2020

Accepted - 10 October 2020

DOI: $10.32677 /$ IJCR.2020.v06.i10.011
$1 \mathrm{~h}$ of birth, the child became lethargic and developed progressive respiratory distress requiring oxygen to maintain saturation.

The baby was shifted to the neonatal intensive care unit and was found to be lethargic, pale with a respiratory rate of 70 breath/ min, a saturation of $70 \%$ at room air, heart rate 140 beats $/ \mathrm{min}$, and capillary refill time of $<3 \mathrm{~s}$ with palpable peripheral pulses. Anterior fontanels were normal and the trachea was central. Suprasternal and subcostal retractions were noted with decreased breath sounds bilaterally on auscultation. The chest X-ray revealed pneumothorax on the right more than the left side (Fig. 1a). The initial sepsis screen was negative. The baby had worsening respiratory distress with a respiratory rate of $80 / \mathrm{min}$, reduced air entry bilaterally, significant retractions, and oxygen requirement. The baby required $10 \mathrm{~L}$ of oxygen by hood box to maintain saturation.

Bilateral needle thoracentesis was done along the midclavicular line in the second intercostal space. Improvement in the clinical condition was noted with the settling of respiratory rate and non-requirement of supplemental oxygen. The baby started taking breastfeeds in the next few hours. The repeat chest $\mathrm{X}$-ray revealed improvement and the child was discharged after 5 days (Fig. 1b). Neurosonogram and abdominal ultrasound (USG) done and showed no anomalies.

\section{DISCUSSION}

Spontaneous pneumothorax is a rare occurrence in term neonates and manifests as progressive respiratory distress starting within a

\footnotetext{
Correspondence to: Dr. Vinson James, Department of Pediatrics, Assumption Hospital, Suthan Bathery, Wayanad-673 592, Kerala, India. E-mail: dr.vinsonjames@ gmail.com

(C) 2020 Creative Commons Attribution-NonCommercial 4.0 International License (CC BY-NC-ND 4.0).
} 


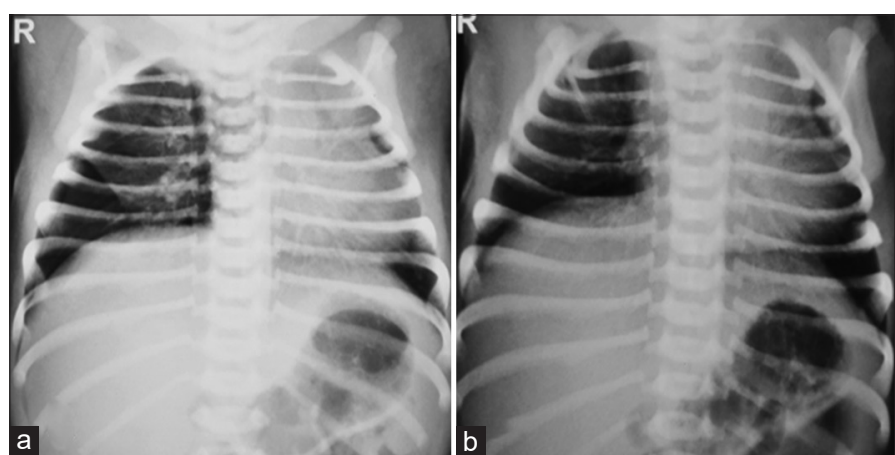

Figure 1: (a) Initial chest $\mathrm{X}$-ray showing bilateral pneumothorax; (b) chest $\mathrm{X}$-ray after bilateral needle thoracentesis

few hours of birth. The incidence of spontaneous pneumothorax varies from $1 \%$ to $2 \%$. Yu et al. studied the clinical course of pneumothorax and its allied condition in 34 newborn infants and found the frequency of pneumothorax to be 3/1000 live births according to a previous study [2]. It may occur spontaneously (idiopathic) or secondary to various underlying lung diseases. Most neonatal pneumothorax, pneumomediastinum, and surgical emphysema in the neck occur as a result of birth injury, shoulder dystonia, prematurity, pneumonia, meconium aspiration syndrome, or assisted ventilation. Spontaneous pneumothorax in a term new-born is a very rare entity. Very few case reports described bilateral spontaneous pneumothorax in a neonate. A similar case was published by Arora et al. in a female neonate with spontaneous pneumothorax and moderate respiratory distress [5].

As the labor progresses, spontaneous pneumothorax occurs due to the overcompression of the rib cage. This causes an abnormal increase in the pressure gradient between the alveolar and perivascular space for a transient period leading to the rupture of the alveoli. This condition can manifest within a few hours of birth and may lead to respiratory distress, which is considered to be the most important presenting sign.

Early recognition of progressive respiratory distress and its immediate management is lifesaving and reduces undue interventions, referrals, escalation of treatment costs, and the hospital stay. Renal and cardiac abnormalities are to be screened by the USG in the presence of spontaneous pneumothorax [3]. Administration of high flow or 100\% oxygen (nitrogen washout therapy) helps in pneumothorax resolution in newborns with mild-to-moderate respiratory distress. In considerable cases of spontaneous pneumothorax, an intercostal drain is used to relieve respiratory distress. Severe distress may warrant needle thoracentesis for symptomatic relief. In case of persistent $\left(>48 \mathrm{~h}\right.$ ) oxygen requirement, low $\mathrm{FiO}_{2}(40-60 \%)$ is used for the management for a long duration $(>48 \mathrm{~h}$ ) of distress [6-8].

The management is mostly associated with assisted ventilation, birth trauma, meconium aspiration, or prematurity. Pneumothorax results in longer hospital stay due to these surgical interventions [9]. Al Tawil et al. conducted a study on 80 newborns with spontaneous pneumothorax in which a majority of them were managed conservatively. Only $7.5 \%$ of symptomatic term infants with spontaneous pneumothorax required chest tube insertion or tube thoracentesis [8].

\section{CONCLUSION}

Early identification of spontaneous pneumothorax and its classification based on the severity helps in providing adequate management. Even in a resource-constrained setting, mildto-moderate distress can be managed conservatively with the help of adequate oxygenation. Severe distress requires needle thoracentesis with clinical improvement noted immediately. Timely diagnosis and adequate management reduces undue referrals and treatment escalation.

\section{REFERENCES}

1. Edwards MO, Kotecha SJ, Kotecha S. Respiratory distress of the term newborn infant. Paediatr Respir Rev 2013;14:29-36.

2. Yu VY, Liew SW, Robertson NR. Pneumothorax in the newborn: Changing pattern. Arch Dis Child 1975;50:449-53.

3. Bashour BN, Balfe JW. Urinary tract anomalies in neonates with spontaneous pneumothorax and/or pneumomediastinum. Pediatrics 1977;59:1048-9.

4. Maya P, Saha SP. Spontaneous pneumothorax in the newborn. Am Surg 1983;49:192-5

5. Arora K, Panda SS, Das RR, Mohanty PK, Panda M. Primary spontaneous bilateral pneumothorax in a neonate. APSP J Case Rep 2014;5:31.

6. Henry M, Arnold T, Harvey J. BTS guidelines for the management of spontaneous pneumothorax. Thorax 2003;58:ii39-52.

7. Katar S, Devecioğlu C, Kervancioğlu M, Ulkü R. Symptomatic spontaneous pneumothorax in term newborns. Pediatr Surg Int 2006;22:755-8.

8. Al Tawil K, Abu-Ekteish FM, Tamimi O, Al Hathal MM, Al Hathlol K, Laimun BA. Symptomatic spontaneous pneumothorax in term newborn infants. Pediatr Pulmonol 2004;37:443-6.

9. Ashkenazi S, Merlob P, Stark H, Einstein B, Grunebaum M, Reisner SH. Renal anomalies in neonates with spontaneous pneumothorax incidence and evaluation. Int J Pediatr Nephrol 1983;4:25-7.

Funding: None; Conflicts of Interest: None Stated.

How to cite this article: James V, Rajan J. Bilateral spontaneous pneumothorax in a term newborn. Indian $\mathrm{J}$ Case Reports. 2020;6(10):578-579. 